\section{PENELITAN MUTU SEPATU KANVAS SOL KARET VULKANISASI DITINJAU DARI KEKUATAN REKAT LEM}

Oleh : Suliestiyah Wrd *), Dwi asdono Basuki **)

\section{ABSTRACT}

This research is aimed at detecting the adhesion strength of adhesive on rulcanized rubber sole canvas shoes. Chiefly adhesion strength between foxing and the shoe upper. The tests carried-out were adhesion test at front inside, back insides, front outsides and back outsides of the shoes. The samples were taken from Kotamadya Yogyakarta. The test result showed that the quality of vulcanized rubber sole canvas shoes complied with the test requirements, approximately $>1.000$ grams $/ \mathrm{cm}^{2}$. The adhesion strength between foxing and the shoe uppers generally ranges between adhesion strength requirements $\left(\mathrm{UCL}_{\overline{\mathrm{x}}}\right.$ and $\left.\mathrm{LCL}_{\overline{\mathrm{x}}}\right)$,

\section{INTISARI}

Penelitian ini bertujuan untuk mengetahui kekuatan rekat lem pada Sepatu Kanvas Sol Karet Vulkanisasi. Khususnya kekuatan rekat antara foxing dengan atasan sepatu, yang meliputi uji kekuatan rekat lem pada sisi dalam depan, sisi dalam belakang, sisi luar depan serta sisi luar belakang.

Daerah penelitian adalah Kodya Yogyakarta. Hasil uji menunjukkan bahwa mutu Sepatu Kanvas Sol Karet Vulkanisasi telah memenuhi syarat uji, yaitu rata-rata $>$ $1.000 \mathrm{gram} / \mathrm{cm}^{2}$

Kekuatan rekat lem antara foxing dengan atasan sepatu secara umum berada dalam batas kendali kekuatan rekat ( $\mathrm{UCL}_{\overline{\mathrm{x}}}$ dan $\mathrm{LCL}_{\overline{\mathrm{x}}}$ ).

*) Balai Besar Penelitian dan Pengembangan Industri Barang Kulit, Karet dan Plastik

**) Akademi Teknologi Kulit.

\section{PENDAHULUAN}

Sepatu sebagai alas kaki merupakan salah satu sarana untuk melindungi kaki selama melakukan aktifitas kerja. Sepatu kanvas adalah salah satu jenis alas kaki (lama manusia untuk melakukan aktifitas kerja ataupun olah raga yang digunakan manusia untuk melakukan aktifitas kerja ataupan mendapatkan sepatu

yantutan konsumen akan dipakai, praktis, tidak membuat sakit serta baik mutunya.
Dalam memenuhi kebutuhan konsumen akan sepatu Olah raga tersebut, maka dewasa ini banyak perusahaan-perusahaan sepatu yang memproduksi sepatu Olah taiki dengan sistem lem (Cemeted Shoes), yaitu sepatu yang konstruksi perakitan antara bagian atasan dengan bawaban (sol) seluruhnya menggunakan perekat lem. Halah satu jenis sepatu sistem lem adalah Sepatu Kanvas Sol Karet Vulkanisasi.

Keistimewaan dari sepatu ini adalah menggunakan sol dari karet kompon dan pada bagian tepi sckeliling bawahan sepatu dipasang foxing, yaitu sejenis pita dari hahan karet kompon dengan te.5 wialah untuk memberi kekuatan rekat yang kuat antara sol luar dengan atasan sepatu (Bati. 1982a). Sedang lem yang digunakan adalah campuran CTBL, latex serta twe nain SBP x sebagai solvent (bata, 1982b).

Houl karet tersebut dicetak secara Vulkanisasi, yaitu dengan suhu $160^{\circ}-180^{\circ} \mathrm{C}$, wakiu proses 7 - 8 menit serta menggunakan tekanan sebesar $200 \mathrm{~kg} / \mathrm{cm}^{2}$ (Bata, 1961)

Kodya Yogyakarta yang merupakan kota pelajar adalah daerah yang potensial uituk pemasaran sepatu olah raga pada umumnya dan Sepatu Kanvas Sol Karet Vulkanisasi pada khususnya.

Untuk mengetahui mutu sepatu kanvas sol karet cetak vulkanisasi, salah satu faktor adalah dengan menguji kekuatan rekat lem antara foxing dengan atasan sepatu. Menurut Bata (1982b) satndard minimum kekuatan rekat lem adalah $1.000 \mathrm{~g} / \mathrm{cm}^{2}$.

Dengan mengetahui mutu sepatu kanvas sol karet vulkanisasi yang dipasarkan di Kodva Yogyakarta ini akan dapat digunakan sebagai bahan informasi bagi para honsumen agar dapat memilih sepatu olah raga yang mutunya telah memenuhi syarat

\section{MATERI DAN METODA}

A. Materi

1. Dalam penelitian ini materi yang digunakan adalah Sepatu Kanvas Sol Karet Vulkanisasi yang dijual dipasaran daerah Kodya Yogyakarta.

2. Alat yang digunakan: Peel adhesion tester, knife clicker dan cutter.

II. Metoda

1. Pengambilan sampel.

Secara Area pusposive sampling, yaitu kodya Yogyakarta dibagi daiam 5 (lima) daerah pasar. Kemudian masing-masing daerah pasar ditetapkan sampel sebanyak 10 buah sepatu (5 pasang), sehingga jumlah sampel seluruhnya adalah 50 buah sepatu. 
2. Pelaksanaan Peneitian Sampel sepatu mendapat perlakuan diuji kekuatan rekat lem pada foxing dengan atasan sepatu, meliputi :
a. Sisi dalam depan
b. Sisi dalam belakang
c. Sisi luar depan
d. sisi luar belakang.

3. Analisa data

Menghitung nilai-nilai batas pengendalian rataan $\bar{x}$ dan nilai-nilai batas pengendalian penvebaran $\mathrm{R}$ (range) dari kekuatan rekat lem antara foxing dengan atasan sepatu

Rumus perhitungan
$\mathrm{a} \cdot \overline{\mathrm{x}}=\sum_{\mathrm{i}=1}^{\mathrm{n}} \mathrm{x}_{1} / \mathrm{n}$
b. $\mathrm{CL}_{\overline{\mathrm{X}}}=\mathrm{x} \pm \mathrm{A}_{2} \overline{\mathrm{R}} \quad\left(\mathrm{UCL}_{\overline{\mathrm{x}}} \mathrm{dan} \mathrm{LCL}_{\overline{\mathrm{X}}}\right)$
c. $\mathrm{UCL}_{\overline{\mathrm{R}}}=\mathrm{D} 4 \overline{\mathrm{R}}$ dan $\mathrm{LCL}_{\mathrm{R}}=\mathrm{D}_{3} \overline{\mathrm{R}}$ (tidak diperhitungkan)

\section{HASIL PENELITIAN DAN PEMBAHASAN}

\section{A. Hasil Penelitian}

Hasil uji kekuatan rekat lem setelah diolah secara statistik menghasilkan data sebagai berikut
Tatuef Rata-rata $(\bar{x})$ kekuatan rekat lem antara foxing dengan atasan sepatu $\left(\mathrm{gram} / \mathrm{cm}^{2}\right)$

\begin{tabular}{|c|c|c|c|c|c|}
\hline \multirow{2}{*}{ No. } & Daerah & \multicolumn{4}{|c|}{ Nilai rata-rata kekuatan rekat } \\
\cline { 3 - 6 } & & 1 & 2 & 3 & 4 \\
\hline Pasar & I & 1.940 & 1.765 & 1.765 & 1.780 \\
2 & II & 2.000 & 1.915 & 1.840 & 1.825 \\
3 & III & 1.825 & 1.850 & 1.800 & 1.850 \\
4 & IV & 1.825 & 1.495 & 1.640 & 1.705 \\
5 & V & 1.855 & 1.865 & 1.870 & 1.840 \\
\hline & Nilai $\bar{x}$ & 1.889 & 1.778 & 1.783 & 1.800 \\
\hline
\end{tabular}

Tatel 2. Scbaran $(\bar{R})$ dari jangkauan kekuatan rekat lem antara foxing dengan atasan sepatu $\left(\mathrm{gram} / \mathrm{cm}^{2}\right)$

\begin{tabular}{|c|c|c|c|c|c|}
\hline \multirow{3}{*}{ No. } & $\begin{array}{c}\text { Daerah } \\
\text { Pasar }\end{array}$ & \multicolumn{4}{|c|}{ Nilai R kekuatan rekat } \\
\cline { 3 - 6 } & & 1 & 2 & 3 & 4 \\
\hline 1. & I & 400 & 1.150 & 950 & 850 \\
2. & II & 250 & 250 & 650 & 650 \\
3. & III & 450 & 650 & 350 & 350 \\
4. & IV & 750 & 1.150 & 800 & 800 \\
5. & V & 650 & 450 & 450 & 350 \\
\hline & Nilai $\bar{R}$ & 500 & 730 & 640 & 600 \\
\hline
\end{tabular}

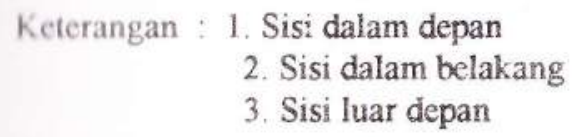

1. Perhitungan nilai batas-batas pengendalian rataan $(\overline{\mathrm{x}})$ kekuatan rekat lem antara foxing dengan atasan sepatu adalah sebagai berikut.

a Sisi dalam depan
UCL $\bar{x}_{1}$
$=1.889+0,308$
$=2.043 \mathrm{gram} / \mathrm{cm}^{2}$
LCL $\bar{x}_{1}$
$=1.889-0,308 \cdot 500$
$=1735 \mathrm{gram} / \mathrm{cm}^{2}$ 
b. Sisi dalam belakang

$\begin{array}{ll}\text { UCL } \bar{x}_{3} & =2.002,84 \mathrm{gram} / \mathrm{cm}^{2} \\ \mathrm{LCL} \overline{\mathrm{x}}_{3} & =1.553,16 \mathrm{gram} / \mathrm{cm}^{2}\end{array}$

c. Sisi luar depan
$\mathrm{UCL} \overline{\mathrm{X}}_{3}$
$=1.980 .80 \mathrm{gram} / \mathrm{cm}^{2}$

LCL $x_{3}$

$=1.585 .88 \mathrm{gram} / \mathrm{cm}^{2}$

d. Sisi luar belakang

$\begin{array}{lll}\text { UCL } \bar{x}_{4} & =1.984,80 \mathrm{gram} / \mathrm{cm}^{2} \\ \text { LCL. } \bar{x}_{4} & =1.615,20 \mathrm{gram} / \mathrm{cm}^{2}\end{array}$

2. Perhitungan nilai batas-batas pengendalian sebaran ( $R$ ) Jangkauan kekuatan rekat antara foxing dengan atasan sepatu adalah sebagai berikut

a. Sisi dalam depan
UCL $\overline{\mathrm{R}}_{1}$
$=1,777 \cdot 500$
$=888,50 \mathrm{gram} / \mathrm{cm}^{2}$

b. Sisi dalam belakang $\mathrm{UCL} \overline{\mathrm{R}}_{1}$

$=1.297,21 \mathrm{gram} / \mathrm{cm}^{2}$

c. Sisi Luar depan UCL R

$=1.137,28 \mathrm{gram} / \mathrm{cm}^{2}$

A. Sisi luar belakang $\mathrm{UCL} \overrightarrow{\mathrm{R}}_{4}$ $=1.066 .20 \mathrm{gram} / \mathrm{cm}^{2}$

Untuk lebih jelasnya berikut ini adalah diagram kontrol/ pengendalian untuk masing-masing perlakuan
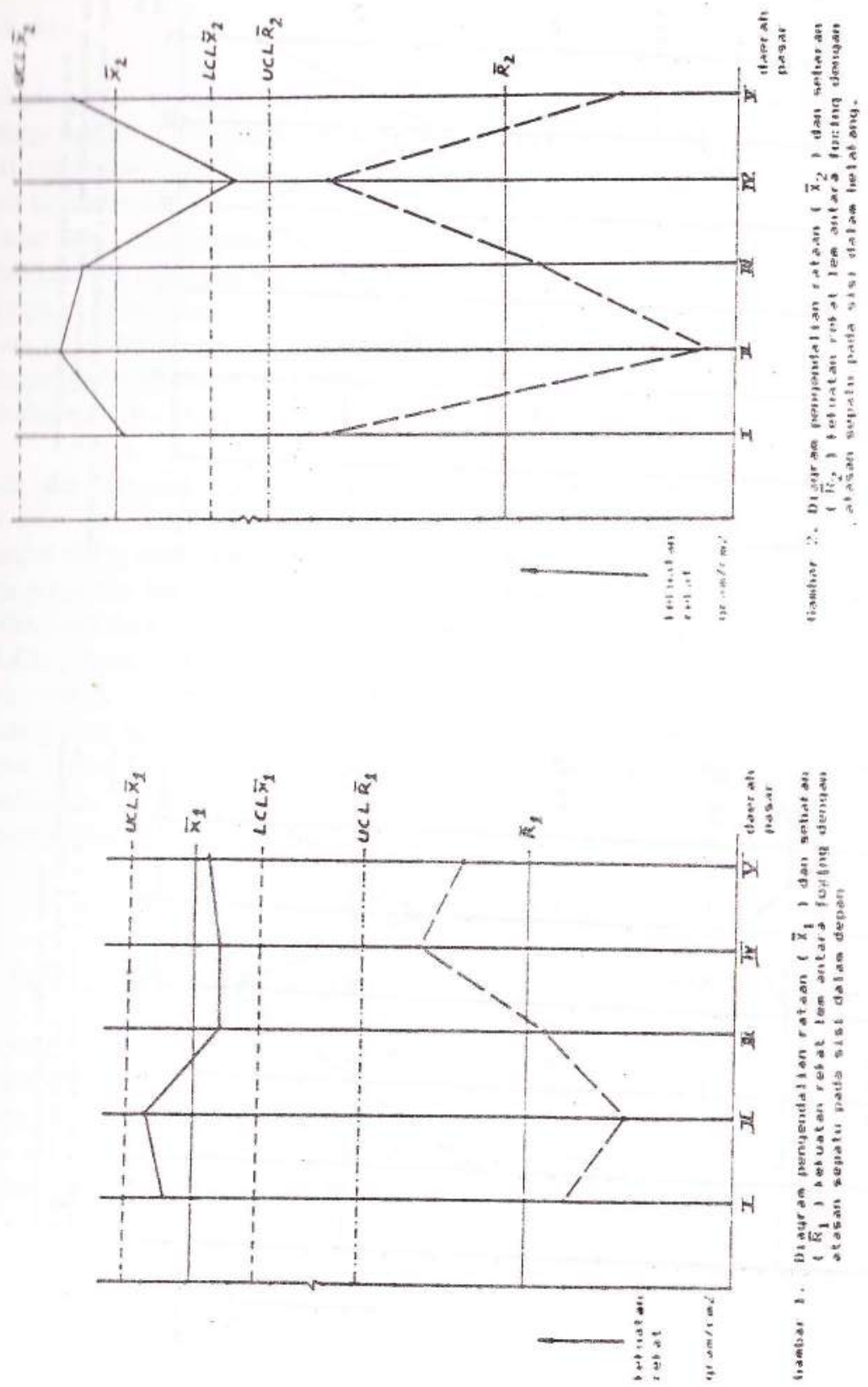


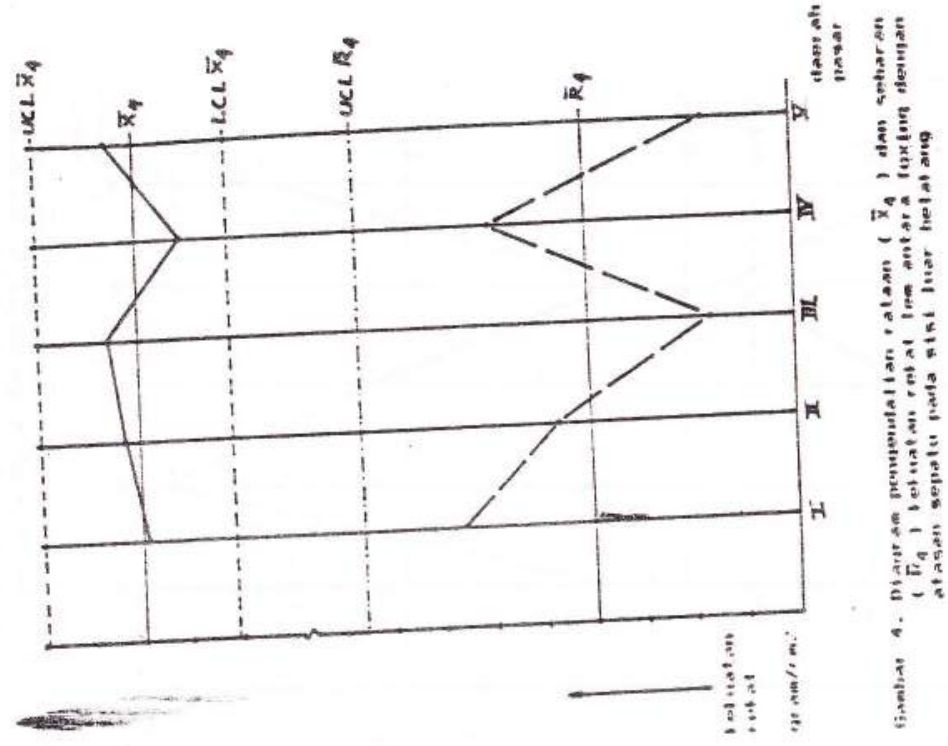

II. Nembahasan

1. Hasil pengujian kekuatan rekat lem antara foxing dengan atasan sepatu yang tertinggi adalah $2.050 \mathrm{gram} / \mathrm{cm}^{2}$ dan terendah adalah $900 \mathrm{gram} / \mathrm{cm}^{2}$.

Hasil pengujian yang kurang dari standard $1.000 \mathrm{gram} / \mathrm{cm}^{2}$ ini disebabkan antara lain karena

a. Kadar lem ( solid content of cement)

b. Pengkasaran pada bidang yang akan di lem.

c. Kerataan olesan lem.

d. Cara pengolesan lem.

c. Kematangan sepatu setelah dimasak didalam boiler pada suhu $134^{\circ} \mathrm{C}$. tekanan uap $8-10 \mathrm{~kg} / \mathrm{cm}^{2}$ selama 50 menit. (Bata, 1982b).

2. Dilihat dari diagram pengendalian rataan $(\bar{x})$ dan sebaran $(\bar{R})$, kekuatan rekat dan lem antara foxing dengan atasan sepatu menunjukkan hasil uji kekuatan rekat lem pada sisi dalam depan, sisi dalam belakang, sisi luar depan serta sisi luar belakang, secara umum semuanya dalam batas kendali dan menunjukkan grafik yang normal, yaitu terletak dalam batas garis $\mathrm{UCL}_{\overline{\mathrm{x}}}$ dan LCL $\bar{x}$ serta UCL $\bar{R}$.

Hanya terdapat 1 (satu) kasus pada hasil uji kekuatan rekat lem sisi dalam belakang pada daerah pasar IV, rata-rata hasil ujinya adalah $1495 \mathrm{gram} / \mathrm{cm}^{2}$ dibawah nilai $\mathrm{LCL} \overline{\mathrm{x}}_{2}$ sebesar $1.553,16 \mathrm{gram} / \mathrm{cm}^{2}$. namun, apabila dibandingkan dengan standard minimum kekuatan rekat sebesar 1.000 $\mathrm{gram} / \mathrm{cm}^{2}$ (Bata,1982b), kekuatan rekat tersebut masih memenuhi syarat uji.

\section{KESIMPULAN}

Dari hasil penelitian dan pembahasan, maka dapat disimpulkan sebagai herikut

1 Mutu Sepatu Kanvas Sol Cetak vulkanisasi yang dipasarkan di daerah Kodya Yogyakarta telah memenuhi syarat uji, bila ditinjau darisegi uji kekuatan rekat lem antara foxing dengan atasan sepatu.

2. Kekuatan rekat lem antara foxing dengan atasan sepatu secara umum berada dalam batas kendali, yaitu terletak diantara batas atas $\left(\mathrm{UCL}_{\overline{\mathrm{x}}}\right)$ dan batas bawah $\left(\mathrm{LCL}_{\overline{\mathrm{x}}}\right)$ 


\section{DAFTAR PUSTAKA}

1. Bata, 1961 Rubber Technology Course, Bata Shoe Co. Private Ltd. Calcutta.

2. Bata, 1982a Prosedure Manual Bulletin, Bata Shoe Co. Private Ltd. Toronto Canada.

3. Bata, 1982 b Production Guide, Build up construction, Bata Shoe Co. Ltd. Jakarta.

4. Sigit Nugroho, 1984 Dasar-dasar analisa Pengendalian Mutu Secara Statistik, Dep. Stastistika \& Komputasi Fak Matematika dan IPA Institut Pertanian Bogor.

5. Thorton, JH, 1955 Texbook of footwear materials, The National Trade Press Lid. London

Lampiran 1. Faktor-faktor yang digunakan untuk menghitung diagram rataan $(\bar{x})$ dan sebaran $(\vec{R})$

\begin{tabular}{|c|c|c|c|c|c|c|}
\hline \multirow{2}{*}{$\begin{array}{c}\text { Sampel } \\
(\mathrm{n})\end{array}$} & \multirow{2}{*}{ d) } & Diagram $\bar{x}$ & \multicolumn{2}{|c|}{ Diagram $R$} & \multicolumn{2}{|c|}{ Diagram S } \\
\hline & & $\mathrm{A}_{2}$ & $\mathrm{D}_{4}$ & $\mathrm{D}_{3}$ & $\mathrm{~B}_{4}$ & $\mathrm{~B}_{3}$ \\
\hline 2 & 1.128 & 1.880 & 3.267 & 0 & 3.267 & 0 \\
\hline 3 & 1.693 & 1.023 & 2.574 & 0 & 2.568 & 0 \\
\hline 4 & 2.059 & 0.729 & 2.282 & 0 & 2.226 & 0 \\
\hline 5 & 2.326 & 0.577 & 2.114 & 0 & 2.089 & 0 \\
\hline 6 & 2.534 & 0.483 & 2.004 & 0 & 1.970 & 0.030 \\
\hline 7 & 2.704 & 0.419 & 1.924 & 0.076 & 1.882 & 0.118 \\
\hline 8 & 2.847 & 0.373 & 1.864 & 0.136 & 1.815 & 0.185 \\
\hline 9 & 2.970 & 0.337 & 1.816 & 0.184 & 1.761 & 0.239 \\
\hline 10 & 3.078 & 0.308 & 1.777 & 0.223 & 1.716 & 0.284 \\
\hline 11 & 3.173 & 0.285 & 1.744 & 0.256 & 1.679 & 0.321 \\
\hline 12 & 3.258 & 0.266 & 1.717 & 0.283 & 1.646 & 0.354 \\
\hline 13 & 3.336 & 0.249 & 1.693 & 0.307 & 1.618 & 0.382 \\
\hline 14 & 3.407 & 0.235 & 1.672 & 0.328 & 1.594 & 0.406 \\
\hline 15 & 3.472 & 0.223 & 1.653 & 0.347 & 1.572 & 0.428 \\
\hline
\end{tabular}

Sumber : ASTM STP 15 D, Manual on presentation of data and control chart analysis, Sigit Nugroho, 1984

s. 